\title{
Effectiveness evaluation on reuse of construction sludges considering uncertainties of environmental economics
}

\author{
Shinya Inazumi ${ }^{\text {i) }}$ and Maya Manabe ${ }^{\text {ii) }}$ \\ i) Associate Professor, Department of Civil Engineering, Akashi College, National Institute of Technology, \\ 679-3, Nishioka, Uozumi, Akashi 674-8501, Japan. \\ ii) Student, Advanced Course of Architecture and Civil Engineering, Akashi College, National Institute of Technology, \\ 679-3, Nishioka, Uozumi, Akashi 674-8501, Japan.
}

\begin{abstract}
In Japan, although the recycling of waste has been promoted, there may be various obstacles. This study focuses on construction waste, more specifically, construction sludge, which is less advanced in terms of recycling. Processing cost for materials recycled from construction sludge is higher compared to the cost of mining virgin materials. There are some additional difficulties including delays in schedules due to the time required for processing and the balance between supply and demand. Therefore, the benefit of recycling by adding the time factor to the evaluation model with consideration for cost and environmental load is quantitatively assessed. As a result, it is shown that the bottlenecks of construction sludge recycling are higher cost than the cost of mining of virgin materials, high heavy metal contents in the construction sludge, and delays in the recycling process.
\end{abstract}

Keywords: environmental economics, environmental impact assessment, construction sludge, recycling

\section{INTRODUCTION}

Although recycling of construction waste is advancing, there are still many problems to be solved. One of the main factors limiting recycling of construction waste is the higher unit price of recycled materials compared to that of virgin materials because of the necessity of processing for recycling. In addition, it takes time for such processing for recycling, and if recycled materials are used, the construction schedules could be extended, resulting in a possible increase in the construction cost. However, it can look upon these problems as being the result of considering recycling only in terms of cost. The purpose of recycling consists of enabling society to undertake sustainable development through environmental preservation. Thus, in evaluating the business potential of waste recycling, not only the required actual cost but also the effects on the environment should be considered. In other words, it is important that business activities related to waste recycling should be evaluated according to environmental economics, which employs a well-balanced consideration between actual cost and environmental effects by accounting internally for environmental impact over the life cycle based on the concept of environmental economics.

In the previous studies regarding construction waste, they examined the environmental impact assessment and environmental accounting approach to evaluate recycling of construction waste by environmental economics in which environmental load converted to environment cost in addition to direct cost is considered (Kunibe et al. 2007; Inazumi et al. 2012). This study focuses on the extension of construction schedules caused by process delay brought about from processing for recycling that is one of the obstacles for recycling of construction waste. Specifically, regarding recycling of construction waste, it use environmental impact assessment and the environmental accounting approach to perform environmental economic evaluation with consideration of process delays in processing for recycling. In this study, among construction waste that is supposed to be a recycling resource, it looks at construction sludge, which is less advanced in terms of recycling.

\section{DEFINITION OF CONSTRUCTION SLUDGE}

\subsection{Present situation of construction sludge}

According to the Ministry of the Environment, the data for industrial waste by industry (2008) shows that the construction industry discharged $700 \times 10^{4}$ tons, $18.9 \%$ of the total, which was the third largest amount (Ministry of the Environment 2008). Similarly, according to the field survey about byproducts of construction by the Ministry of Land, Infrastructure, Transport and Tourism, the data for construction waste by item (2008) shows construction sludge was $450 \times 10^{4}$ tons (Ministry of Land, Infrastructure, Transport and Tourism 2008). Construction sludge did not constitute 
such a large proportion of the total construction waste, but the data for the final disposal by item of construction waste (2008) shows that construction sludge was $67 \times 10^{4}$ tons, approximately $15 \%$ of the total construction waste, $402 \times 10^{4}$ tons (Ministry of Land, Infrastructure, Transport and Tourism 2008). When it is compared with the previous field survey of construction byproducts (2005), it can be considered that the situation regarding the final disposal of construction sludge improved, because the final disposal of construction sludge was $192 \times 10^{4}$ tons and it constituted approximately $30 \%$ of the total, but it was still a large proportion (Ministry of Land, Infrastructure, Transport and Tourism 2006). On the other hand, as for the recycling of construction waste in 2008, the total recycling rate was $93.7 \%$, and the recycling rate of construction sludge was $85.1 \%$ (Ministry of Land, Infrastructure, Transport and Tourism 2008). This was also an improvement from the previous survey. However, the recycling rate for construction sludge was still smaller than the rate for the other construction waste. The recycling rate is defined as a percentage of the recycled amount or the reduced amount against the total amount. And the effective availability rate of displaced soil at construction is defined as a percentage of the displaced soil at construction against the total soil used for construction.

\subsection{Obstacle for recycling of construction sludge}

It is preferable to use the discharged construction sludge during the construction period. However, according to the field survey of construction byproducts in 2008, the percentage of the use during the construction period was only $2 \%$ (Ministry of Land, Infrastructure, Transport and Tourism 2008). This was because there are few facilities available for recycling and it required long distance transportation between a construction site and a processing facility in many cases. In other words, transportation cost increases and furthermore, lots of air pollution is produced. In addition, for recycling of construction sludge there should be construction sludge in the first place. Even if construction needs recycled materials, recycled materials cannot be supplied without construction sludge at the processing facility. In addition to these disadvantages, recycling takes time and it may cause a delay in construction. If the construction schedule is delayed, it will lead to an increase in costs, such as labor cost or lease payments for the equipment. Thus, constructors are forced to use virgin materials instead of recycled materials. The possible delay in the construction schedule is one of the obstacles for the recycling of construction sludge.

\section{ENVIRONMENT IMPACT ASSESSMENT AND ENVIRONMENTAL ACCOUNTING APPROACH}

\subsection{Quantification of direct cost}

For recycling of construction waste, an inevitable cost including transportation cost and processing cost for recycling is required. This study refers to these types of cost as direct cost. When it roughly classifies them, we have an initial cost and running cost (including processing cost, transportation cost and storing cost) (Matsuo et al. 1999). The direct cost can be calculated by Eq. (1). This study applies Eq. (1) to the manufacturing of virgin materials, manufacturing of recycled materials and disposal. The elements in Eq. (1) indicate unit price of unit construction work.

$C=C_{I}+C_{S}+C_{T}+C_{K}$

$C_{S}=W S \quad C_{T}=W L T \quad C_{K}=W D K$

Where, $C$ : direct cost (yen), $C_{I}$ : initial cost (yen), $C_{S}$ : processing cost (yen), $C_{T}$ : transportation (yen), $C_{K}$ : storing cost (yen), $W$ : mass (t), $S$ : unit price required for processing of each material $\left(\mathrm{yen} / \mathrm{m}^{3}\right), L$ : transportation distance $(\mathrm{km}), T$ : unit price required for transportation (yen $/ \mathrm{t} \cdot \mathrm{km}), D$ : storing days (day), $K$ : unit price required for storing each material (yen/t·day).

\subsection{Quantification of environmental cost}

It is necessary for people to understand environmental value through its conversion into monetary value. This study refers to detected environmental load converted into a cost-based figure just like direct cost as environmental cost.

In the evaluation and comparison based on environmental economic efficiency performed in this study, Eq. (2) shows the environmental cost element to which this study pays special attention. This study applies Eq. (2) to the manufacturing of virgin materials, manufacturing of recycled materials and disposal. Each element in Eq. (2) indicates the unit price of unit construction work. Here, it refers to the results of the study of (Omine and Matsuyuki 2003; Omine 2007) and other previous studies (Inazumi et al. 2012) for extraction of environmental cost elements.

$E=E_{O}+E_{T}+E_{C 1}+E_{C 2}+E_{C 3}+E_{C 4}$

Where, $E$ : environmental cost (yen), $E_{O}$ : environmental cost accompanied with operation of facilities (yen), $E_{T}$ : environmental cost accompanied with transportation (yen), $E_{C 1}$ : environmental cost related to public functions such as forests (yen), $E_{C 2}$ : environmental cost related to impact on ecological system (yen), $E_{C 3}$ : environmental cost related to exploitation of natural resources (yen), $E_{C 4}$ : environmental cost related to worsening of residential environment (yen). 


\subsection{Business effect on recycling of construction waste}

It is thought that recycling of construction waste contributes to the slowdown in the decrease of the remaining capacity of the final disposal sites through reduction of waste, and to cost reduction of waste disposal (Agriculture, Forestry and Fishers Bio Recycling Laboratory System Team 2006). This study regards these benefits of recycling as business effects caused by reduction of cost required for waste disposal. The evaluation of the business effect is calculated by multiplying the amount of construction waste by the unit price of final disposal as shown in Eq. (3). However, since the business effect means cost reduction, the calculated result should be a negative value.

$B=-W \times S$

Where, $B$ : business effect of recycling of construction waste (yen), $W$ : amount of construction waste $\left(\mathrm{m}^{3}\right), S$ : unit price of final disposal $\left(\right.$ yen $\left./ \mathrm{m}^{3}\right)$.

\subsection{Total cost}

The environmental assessment and environmental accounting approach defines the total cost shown by Eq. (4) as one of the indexes of environmental economic efficiency. The total cost is considered as a social cost with consideration of the environmental impact.

$T=C+E+B$

Where, $T$ : total cost (yen), $C$ : direct cost (yen), $E$ : environmental cost (yen), $B$ : business effect by recycling (yen).

\subsection{Consideration of delay in processing process}

One of the obstacles for recycling is that the supply of recycled materials does not fit well with the construction schedule (Ministry of Land, Infrastructure, Transport and Tourism 2006). This is because the recycling of construction waste has some uncertainties including that construction waste is not constantly supplied to the disposal site, that it takes time for recycling to be certified because the method of recycling is complicated or imprecise, and that the time required for processing fluctuates because the quality of construction waste varies depending on the site. As a countermeasure to any delay that may occur in the process of disposal, storage of waste at the stockyard has been proposed. This study assumes soil material used for soil structures can be stored until the specified storage capacity of the site is reached. The number of days for storage is determined by the amount that can be dug in a day in case of virgin material or by the amount that can be manufactured in a day in case of recycled material. If the material stays at the stockyard long, the cost for storage increases. The number of days for storage is defined by Eq. (5).

$D=W / W_{i}$

Where, $D$ : the number of days for storage (day), $W$ : required amount of soil for a soil structure $\left(\mathrm{m}^{3}\right), W_{i}$ : amount of soil (virgin or recycled) that can be produced in a day $\left(\mathrm{m}^{3} /\right.$ day $)$.

\subsection{Evaluation by Monte-Carlo simulation}

There are various approaches to analyze the recycling of construction waste while considering every uncertainty. This study adopted the Monte Carlo simulation. The Monte Carlo simulation is a technique to comprehend all the possible combinations by changing every uncertain element at the same time. By using the Monte Carlo simulation, it can obtain frequency distributions of the output and apply the results to evaluate business risk.

\section{EVALUATION OF ENVIRONMENTAL ECONOMIC EFFICIENCY OF CONSTRUCTION SLUDGE RECYCLING}

This study applies the environmental impact assessment and environmental accounting approach to recycling of construction waste and perform evaluation and comparison of virgin materials (not regenerated soil materials) and recycled materials (regenerated construction sledge) based on environmental economic efficiency.

\subsection{Assumptions}

The following are assumptions for evaluation and comparison for recycling of construction sledge based on environmental economic efficiency.

(1) The amount of soil for the target soil structure is $3,000 \mathrm{~m}^{3}$.

(2) For each element of uncertainty, the minimum, median (base case) and maximum are specified as shown in Table 1. It decided the medians either from the averages of the values in literature search or based on what this study obtained from interviews (Omine and Matsuyuki 2003; Advanced Construction Technology Center 1999; Itsubo and Inaba 2005).

(3) The processing for recycling of construction sledge is a stable treatment.

(4) As shown in Fig. 1, when the processing cost increases, the amount of materials and energy required for processing as well as the environmental cost accompanied with operation of the facility (processing) increase.

(5) For mining, the rate of change is assumed. When soil is dug up, gaps appear in the soil. As a result, the mass of the soil on the ground or after mining becomes larger than the mass after compaction. This rate of change in soil mass is defined as the 
Table 1. Minimum, medium, maximum value in each uncertainty factor.

\begin{tabular}{|l|c|c|c|}
\hline & $\begin{array}{c}\text { Min. } \\
\text { value }\end{array}$ & $\begin{array}{c}\text { Med. } \\
\text { value }\end{array}$ & $\begin{array}{c}\text { Max. } \\
\text { value }\end{array}$ \\
\hline $\begin{array}{l}\text { Volume of compacted soils } \\
\left(\mathrm{m}^{3}\right)\end{array}$ & - & 3,000 & - \\
\hline Volume of mining $\left(\mathrm{m}^{3} / \mathrm{day}\right)$ & - & 600 & - \\
\hline $\begin{array}{l}\text { Volume of recycling } \\
\left(\mathrm{m}^{3} / \mathrm{day}\right)\end{array}$ & - & 600 & - \\
\hline Mining cost (yen $\left./ \mathrm{m}^{3}\right)$ & 1,000 & 3,000 & 5,000 \\
\hline $\begin{array}{l}\text { Recycling processing cost } \\
\left(\text { yen } / \mathrm{m}^{3}\right)\end{array}$ & 2,000 & 5,000 & 8,000 \\
\hline Storing cost (yen $/ \mathrm{m}^{3} /$ day) & - & 1,500 & - \\
\hline $\begin{array}{l}\text { Unit cost of final disposal } \\
\left(\text { yen } / \mathrm{m}^{3}\right)\end{array}$ & 4,000 & 7,000 & 10,000 \\
\hline $\begin{array}{l}\text { Unit cost of transportation } \\
(\text { yen } / \mathrm{t} / \mathrm{km})\end{array}$ & 58 & 68 & 83 \\
\hline $\begin{array}{l}\text { Rate of change volume of } \\
\text { soils }\end{array}$ & 1.26 & 1.47 & 1.70 \\
\hline$\Delta \mathrm{NPP}$ metals contents & 0 & 2 & 9 \\
\hline $\begin{array}{l}\text { Heavy mo } \\
(\mathrm{mg} / \mathrm{kg})\end{array}$ & - & 0.1 & - \\
\hline Mining area (ha) & & & 150 \\
\hline
\end{tabular}

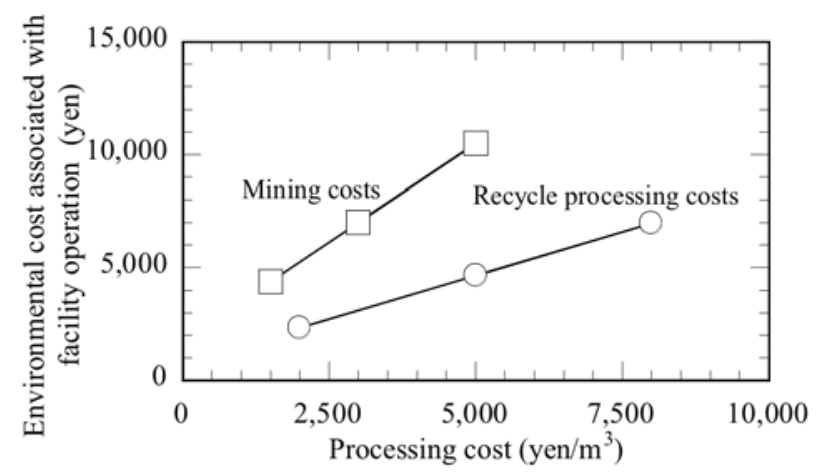

Fig. 1. The relation between processing cost and environmental cost.

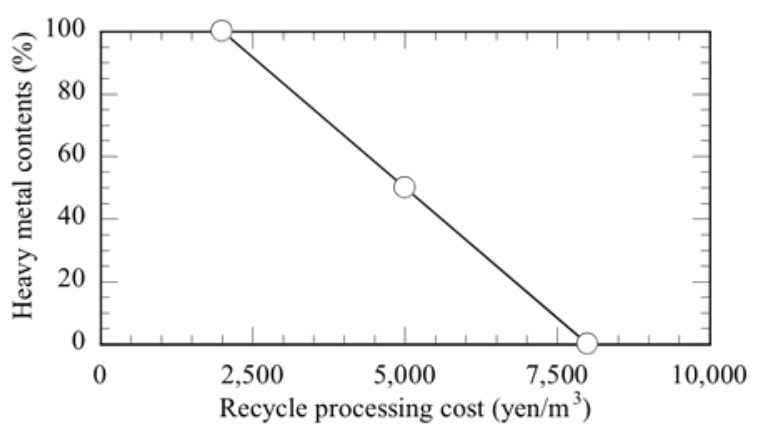

Fig. 2. The relation between processing cost and heavy metal contents.

soil conversion factor.

(6) The quality of virgin material and recycled material is assumed to be same and it is assumed that there is no difference in construction technique.

(7) The material (virgin and recycled) for a soil structure is used $100 \%$ without being discarded.

(8) The possible heavy metal contained in construction sledge is lead $(\mathrm{Pb})$.
(9) When the cost of processing for recycling increases, the heavy metal content in the recycled soil will be reduced as shown in the Fig. 2. This study assumes the removal of heavy metals is included in processing for recycling.

(10) Virgin material and recycled material are stored in the stockyard and the construction work starts when the amount in storage reaches the amount required for the construction work.

(11) Recycled material receives caring at the stockyard for three days.

Heavy metals contained in construction sludge can be an obstacle to recycling, but in fact there are few examples of heavy metals contained in recycled materials (Ministry of Land, Infrastructure, Transport and Tourism 2008). At the same time, the Guideline for construction sludge recycling (Advanced Construction Technology Center 1999) under the editorship of the Ministry of Construction does not specifically mention the measures related to heavy metals contained in recycled materials. Thus, this study uses two assumptions for calculating environmental cost. One is recycled material contains heavy metals and the other is recycled material does not contain heavy metals. The latter assumption does not consider environmental cost regarding the ecosystem.

\subsection{In case of no delay of processing for recycling}

Figs. 3 and 4 show the results of the Monte Carlo simulation focusing on total cost (histograms show frequency distributions). They show two cases: recycled material contains heavy metals and recycled material does not contain heavy metals. In the case of recycled material does not contain heavy metals, for $96.8 \%$ of all the results, the appraisal value became 0 or larger, which means recycled material is superior to virgin material in terms of total cost. In summary, the environmental economic efficiency of recycled material is better than that of virgin material in most of the cases. On the contrary, in case of recycled material contains heavy metals, for $78.3 \%$ of all the results, the appraisal value became 0 or larger, which means the probability that recycled material is superior in economic efficiency to virgin material is rather high. However, it has been clarified that the significance of the evaluation regarding recycling of construction sludge becomes far larger when evaluated by total cost considering the load on the environment than when evaluated only by direct cost.

Yet there is a case in which recycling is not necessary even when evaluated by total cost, and analysis of such cases should be undertaken. Nevertheless, it takes many labor hours to analyze a great number of uncertainties, which may bring about an obstacle to recycling because of the cost increase or a delay in the construction schedule. Therefore, it considered that this study should focus on uncertain elements that have large influences and seek the 


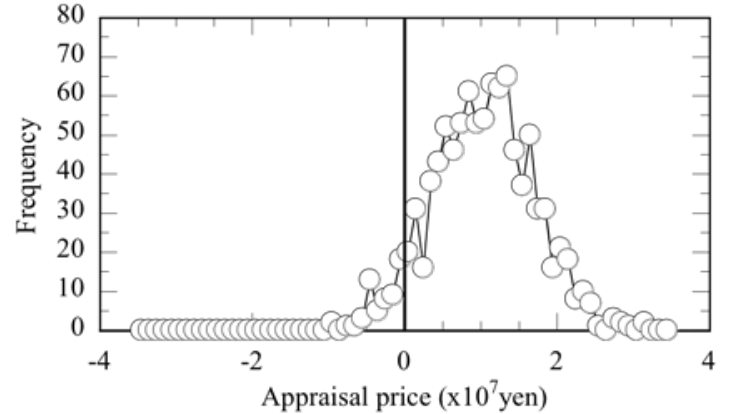

Fig. 3. The result of Monte Carlo simulation when heavy metals are not considered in case of No delay.

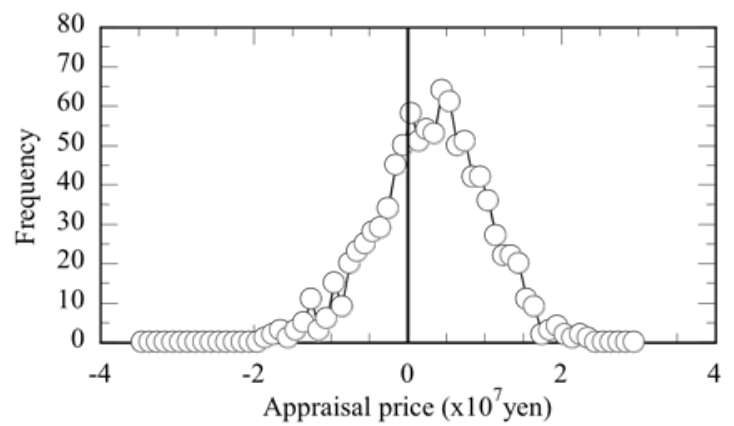

Fig. 4. The result of Monte Carlo simulation when heavy metals are considered in case of No delay.

Table 2. Acquired correlations in case of No delay.

\begin{tabular}{|l|c|c|}
\hline & $\begin{array}{c}\text { Heavy metals are } \\
\text { not considered }\end{array}$ & $\begin{array}{c}\text { Heavy metals } \\
\text { are considered }\end{array}$ \\
\hline Mining cost & 0.421 & 0.371 \\
\hline Recycling processing cost & -0.602 & -0.121 \\
\hline Final disposal cost & 0.577 & 0.545 \\
\hline Unit cost of transportation & -0.072 & -0.069 \\
\hline $\begin{array}{l}\text { Transported distance in } \\
\text { virgin materials }\end{array}$ & 0.12 & 0.101 \\
\hline $\begin{array}{l}\text { Transported distance in } \\
\text { recycling materials }\end{array}$ & -0.163 & -0.119 \\
\hline$\Delta$ NPP & 0.054 & 0.017 \\
\hline Heavy metal contents & - & -0.599 \\
\hline
\end{tabular}

Table 3. The degree of correlations.

\begin{tabular}{|c|c|}
\hline $\pm 0.7 \sim \pm 1$ & High correlation \\
\hline $\pm 0.4 \sim \pm 0.7$ & Medium correlation \\
\hline $\pm 02 \sim \pm 0.4$ & Low correlation \\
\hline $\pm 0 \sim \pm 0.2$ & Little correlation \\
\hline
\end{tabular}

correlation between uncertain elements and appraisal value. Tables 2 and 3 show the acquired correlations and the degree of the correlations. Here, positive correlation implies that the appraisal value increases as the value of uncertain element increases, while negative correlation implies that the appraisal value decreases as the value of uncertain elements decreases. Table 2 shows that for recycled material that does not contain heavy metals the mining cost has the positive correlation of the medium degree and the processing cost for recycling has the negative correlation of the high degree, and that for recycled material that contains heavy metals, similarly, the mining cost has the positive correlation of the medium degree and the inclusion of heavy metals has the negative correlation of the high degree. In addition, for both cases, the disposal cost, meaning the business effect of recycling of construction sludge, has the correlation of the high degree. According to these results, especially mining cost, processing cost for recycling, content of heavy metals and final disposal cost are important when it analyzes the environmental economic efficiency of recycled materials. These four become important indexes in order to promote recycling of construction sludge.

\subsection{In case of delay of processing for recycling}

Similarly previous section conducted an assessment by using the appraisal value which is the differential of the total cost between virgin material and recycled material as the index. When it compared recycled material that does not contain heavy metals with virgin material, the probability of the appraisal value being 0 or larger, meaning recycled material that does not contain heavy metals is superior, was $76.2 \%$. In contrast, when it compared recycled material that contains heavy metals with virgin material, the probability of recycled material that contains heavy metals being superior became $40.5 \%$ (see Figs. 5 and 6 ) Here, this study conducted an assessment of the case without considering a process delay of processing for recycling, and the resultant probabilities are as follows: the probabilities of the appraisal value being 0 or larger became $96.8 \%$ for the case of recycled material does not contain heavy metals and $78.3 \%$ for the case of recycled material contains heavy metals. In summary, the result showed process delay of processing for recycling caused the usefulness of recycling to be reduced.

In case of considering a process delay of processing for recycling, the usefulness of recycling decreases and more detailed pre-examination is required. Table 4 shows the correlation between uncertain elements and appraisal values. For recycled material does not contain heavy metals, the manufacturing amount of recycled material as well as the disposal cost have positive correlations to the medium degree, and the processing cost for recycling has a negative correlation to the medium degree. Also for recycled material contains heavy metals, the manufacturing amount of recycled material as well as the disposal cost has positive correlations to the medium degree. In addition, it was found that the content of heavy metals has a negative correlation to the medium degree. According to these findings, the stable manufacture and supply of recycled material has a very large influence. In order to promote recycling, it is essential to establish a system in which the stable supply of recycled material can be performed. In particular, information about the quality and the amount of soil material required for construction of a 


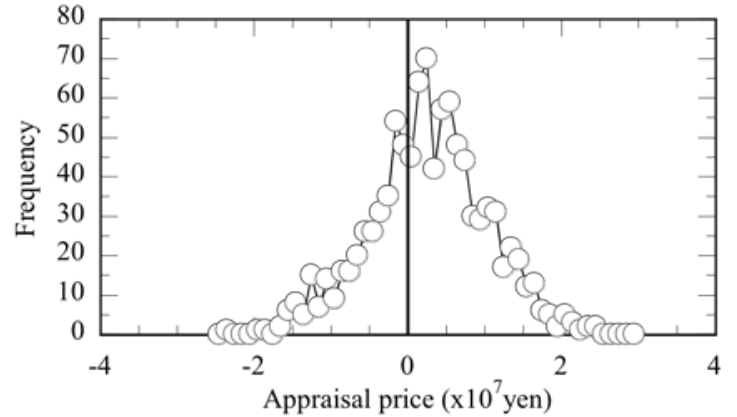

Fig. 5. The result of Monte Carlo simulation when heavy metals are not considered in case of Delay.

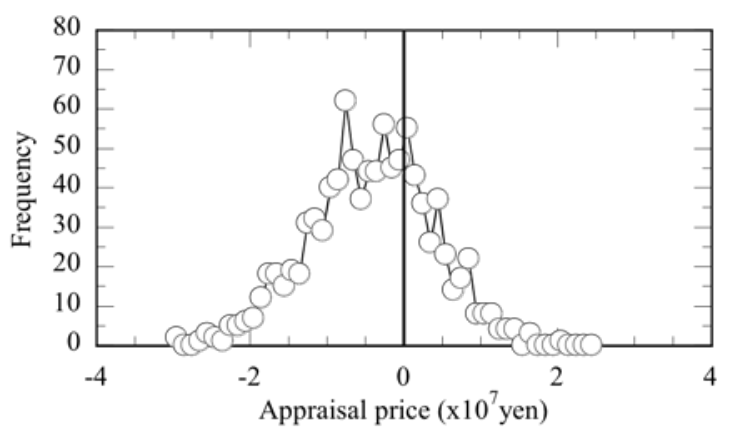

Fig. 6. The result of Monte Carlo simulation when heavy metals are considered in case of Delay.

Table 4. Acquired correlations in case of Delay.

\begin{tabular}{|l|c|c|}
\hline & $\begin{array}{c}\text { Heavy metals are } \\
\text { not considered }\end{array}$ & $\begin{array}{c}\text { Heavy metals are } \\
\text { considered }\end{array}$ \\
\hline Volume of recycling & 0.556 & 0.518 \\
\hline Mining cost & 0.338 & 0.298 \\
\hline $\begin{array}{l}\text { Recycling processing } \\
\text { cost }\end{array}$ & -0.455 & -0.094 \\
\hline Final disposal cost & 0.468 & 0.471 \\
\hline $\begin{array}{l}\text { Unit cost of } \\
\text { transportation }\end{array}$ & -0.049 & -0.055 \\
\hline $\begin{array}{l}\text { Transported distance in } \\
\text { virgin materials }\end{array}$ & 0.029 & 0.037 \\
\hline $\begin{array}{l}\text { Transported distance in } \\
\text { recycling materials }\end{array}$ & -0.168 & -0.159 \\
\hline$\Delta$ NPP & -0.046 & -0.011 \\
\hline Heavy metal contents & - & -0.484 \\
\hline
\end{tabular}

soil structure as well as about the manufacturing amount at a facility of processing of recycling should be closely shared among the related parties. This way, the supply and demand of soil material can be comprehended precisely, and more flexible use of virgin and recycled materials can be performed, so that the bad effects of a process delay of processing for recycling of construction sludge can be controlled.

\section{CONCLUSIONS}

The results obtained are as follows:

(1) Regarding evaluation and comparison of environmental economic efficiency of recycling of construction waste, this study could include the environmental load that was not convertible into
$\mathrm{CO}_{2}$ in the cost base in addition to the conventional cost depending only on $\mathrm{CO}_{2}$ emissions. This way was able to combine environmental load and direct cost, which have different dimensions, and create a new index: total cost.

(2) By performing evaluation and comparison of environmental economic efficiency through the Monte Carlo simulation, this study considered the uncertainty of assumed elements. And it showed that the relative significance of evaluation regarding recycling of construction sludge increased when evaluated by total cost than when evaluated only by direct cost.

(3) It showed the usefulness of recycling decreased quantitatively by considering a process delay in processing for recycling owing to unstable supply of construction sludge as well as a variance in the period required for processing for recycling.

(4) It clarified that limiting factors for recycling of construction sludge include the processing cost.

(5) Recycling is higher than the mining cost of virgin material, construction sludge contains heavy metals and a process delay in processing for recycling.

\section{REFERENCES}

1) Advanced Construction Technology Center (1999): The Guideline in Construction Sludge, Taisei Publishing.

2) Agriculture, Forestry and Fishers Bio Recycling Laboratory System Team (2006): Design and Analysis of Biomass Utilization System, National Institute for Rural Engineering.

3) Inazumi, S., Ohtsu, H., Isoda, T. and Shigematsu, Y. (2012): Evaluation of social environmental efficiency on recycling of construction sludges as ground materials, JSCE Journal of Geotechnical Engineering, 68(1), 163-174.

4) Itsubo, T. and Inaba, A. (2005): Life-cycle Impact Assessment Method based on Endpoint Modeling, Maruzen Publishing.

5) Kunibe, K., Itsubo, T. and Mizuguchi, T. (2007): Environmental Accounting, Yuhikaku Publishing.

6) Matsuo, M. and Honjo, Y. (1999): New View of Geotechnical and Environmental Engineering -The Efficient Use of Displaced Soils at Construction-, Gihodo Shuppan.

7) Ministry of Land, Infrastructure, Transport and Tourism (2006): The Report of the Investigation of Construction Waste in 2006, Announce Document, Ministry of Land, Infrastructure, Transport and Tourism.

8) Ministry of Land, Infrastructure, Transport and Tourism (2008): The Report of the Investigation of Construction Waste in 2008, Announce Document, Ministry of Land, Infrastructure, Transport and Tourism.

9) Ministry of the Environment (2008): The Report of the Emission and Disposition of Industrial Waste in 2008, Announce Document, Ministry of the Environment.

10) Omine, K. (2007): Life cycle assessment, The Magazine of the Japanese Geotechnical Society, 55(10), 40-41.

11) Omine, K. and Matsuyuki, K. (2003): Environmental economic model for recycling of construction surplus soil and waste material, The Magazine of the Japanese Geotechnical Society, 51(5), 10-12. 